\title{
Investigation of Longitudinal Elastic Wave at Right-Angle Joint of Two Rods
}

\author{
Ming-Te Liang \\ Associate Professor, Department of Harbor and River Engineering National Taiwan Ocean Universiry Keelung. Taiwan. \\ Chiou-Jenn Chen \\ Teaching Assistant, Department of Harbor and River Engineering National Taiwan Ocean University Keelung, Taiwan.
}

Follow this and additional works at: https://jmstt.ntou.edu.tw/journal

Part of the Civil and Environmental Engineering Commons

\section{Recommended Citation}

Liang, Ming-Te and Chen, Chiou-Jenn (1998) "Investigation of Longitudinal Elastic Wave at Right-Angle Joint of Two Rods," Journal of Marine Science and Technology. Vol. 6: Iss. 1, Article 6.

DOI: $10.51400 / 2709-6998.2519$

Available at: https://jmstt.ntou.edu.tw/journal/vol6/iss1/6

This Research Article is brought to you for free and open access by Journal of Marine Science and Technology. It has been accepted for inclusion in Journal of Marine Science and Technology by an authorized editor of Journal of Marine Science and Technology. 


\title{
INVESTIGATION OF LONGITUDINAL ELASTIC WAVE AT RIGHT-ANGLE JOINT OF TWO RODS
}

\author{
Ming-Te Liang* and Chiou-Jenn Chen**
}

Keywords: Incident, Reflection, Transmission.

\section{ABSTRACT}

The right-angle welded joint is usefully and frequently used in the welded type for the steel structures. The present study is focused on the longitudinal elastic waves propagating through the right-angle welded joint of two rods. One uses the theory and numerical calculation to identify the consequence of the problems of reflection and transmission. The present study indicates that the incident longitudinal elastic waves are almost reflected in the horizontal rod while the values of $3 \%$ of the generated pulse are transmitted in the vertical rod.

\section{INTRODUCTION}

Welded construction is one of basic industries. Cars, locomotives, space shuttles, aircraft, ships, offshore platforms and power plants are all necessary to manufacture or construct by using weld. Steel rod butt weld is very popular to be used in basic industries. However, steel rod butt weld always has many defects. How to detect these flaws is very much valuable to do investigation.

Mandel et al. [1] studied the problem of stresswave propagation through a right-angle joint by using the method of characteristics, and also experimentally verified their theoretical analysis. Lee and Kolsky [2] used the Timoshenko beam equation $[3,4]$ and applied the method of Fourier synthesis to investigate the problems of longitudinal stress waves transmitted into the welded point with an obtuse or right angle and also experimentally verified their theoretical analyses. When two straight rods of equal square cross-

Paper Received October, 1997. Revised March, 1998. Accepted March, 1998. Author for Correspondence: Ming-Te Liang.

*Associate Professor, Department of Harbor and River Engineering National Taiwan Ocean University Keelung, Taiwan.

**Teaching Assistant, Department of Harbor and River Engineering National Taiwan Ocean University Keelung, Taiwan. section are joined at right angles with a full penetration butt weld, there would be no transmission of longitudinal stress waves into the perpendicular branch. Atkins and Hunter [5] explored the problem of longitudinal elastic waves transmitted right-angled corners in rods of square cross-section. It was found that the values of longitudinal elastic waves propagated were not existed in the perpendicular branch through the experimental strain values compared with the theoretically predictive values. It is worth pointing out that Atkins and Hunter [5] did not give the values of incident, reflection and transmitted waves and time scale for Fig. 4 and Fig. 9 in the paper of [5]. Simha and Fourney [6] extended the Atkins-Hunter equation [5] to present a general formulation for the analysis of stress wave propagation through a junction of rectangular rods. They concluded that a longitudinal stress wave in the horizontal rod is not transmitted into the perpendicular branch. Wu and Lundberg [7] dealed with harmonic elastic wave in a uniform rod with a semi-infinite straight input section, a bend with constant radius of curvature and a semi-infinite straight output section. For a sharp right-angle bend, the energy flux of the transmitted extensional wave is up to $4 \%$ of that of the incident extensional wave, depending on the frequency.

This paper is focused on the study of the theoretical treatment of the refection and transmission of a longitudinal elastic wave around elastic right-angled joint in two rods of square cross-section. In order to study, two straight rods of equal square cross-section are joined at right angles with a full penetration butt weld, ground back to the original cross-section. The region of butt weld is assumed to behave as a elastic body. The effects of the cross-section dimensions of butt weld were neglected. The theoretical analysis is applied to the L-type and is used to theoretically predict the passage of longitudinal elastic waves through the junction. One practical example is referred to illustrating case study. Finally, the conclusion are drawn down. 


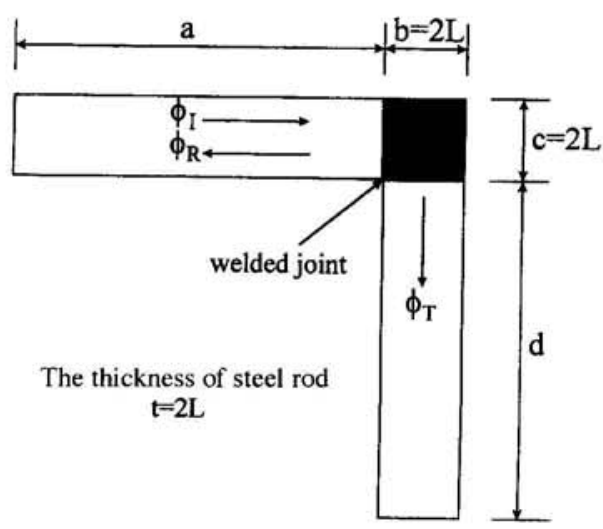

(a) The L-type joint rod

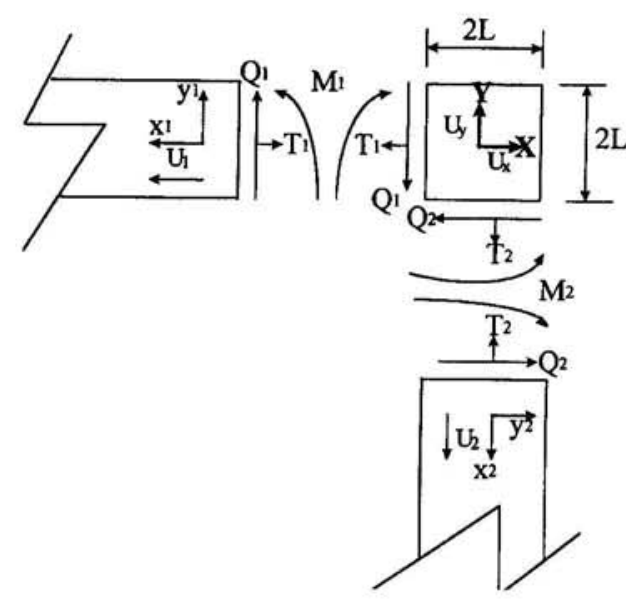

(b) Free-body diagram

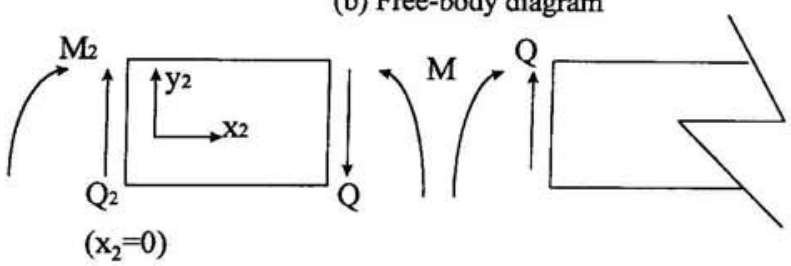

(c) The free-body diagram for vertical rod bending problem

Fig. 1. L-type joint rod and its free-body diagram. The physical properties of the steel rod are as follows: unit weight $g=77 \mathrm{KN} /$ $\mathrm{m}^{3}$, density $\rho=7850 \mathrm{Kg} / \mathrm{m}^{3}$, Young's modulus $\mathrm{E}=200 \mathrm{Gpa}$, shear modulus $\mathrm{G}=80 \mathrm{Gpa}$ and Possion's ratio $v=0.3$.

\section{THEORETICAL FORMULATION}

Figure 1 indicates the L-type joint rod and its free-body diagram. The $L$-section decomposed into two rods of uniform and equal square cross-section of side $2 L$ together with a cube of side $2 L$. In the system of local coordinates for the individual rod, the horizontal and vertical rods are respectively adopted the second and first quadrant. In the system of general coordinates, the first quadrant is adopted. In the Fig. 2, $\theta$ is very infinitesimal. From the displacement

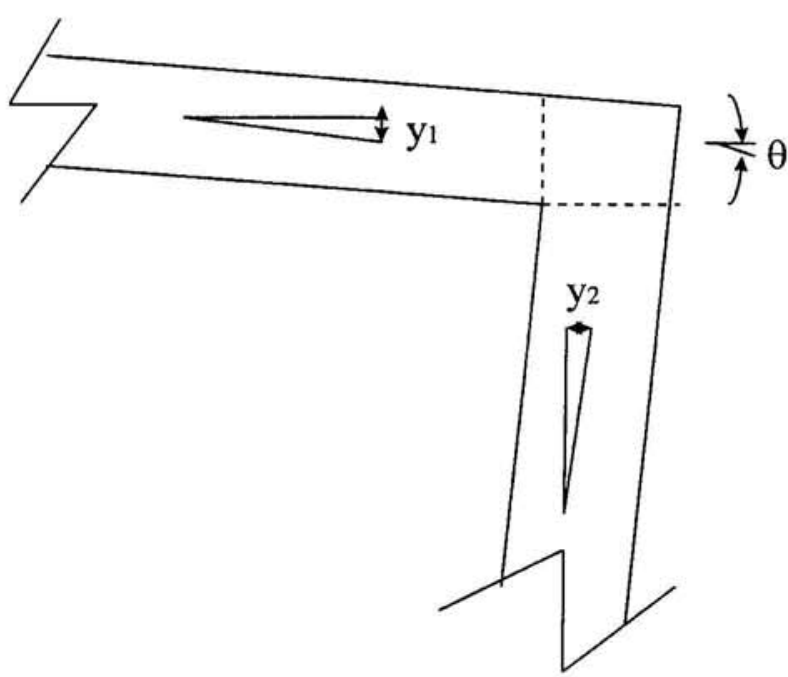

Fig. 2. The deformation of L-type joint rod.

relationship, one knows

$$
U_{x}=X+\theta y, U_{y}=Y-\theta x
$$

In the case of the symmetric mass center, the moment of inertia for the mass is

$$
I_{1}=\frac{16 \rho L^{5}}{3},
$$

where $\rho$ is density.

The second moment of inertia is

$$
I_{2}=\frac{4 L^{4}}{3} \text {. }
$$

The mass of per unit length is

$$
m=4 \rho L^{2} .
$$

From Fig. 1 and the definition of rotational angle, one knows that the horizontal and vertical rod is respectively

$$
\begin{aligned}
& \left(\frac{d y_{1}}{d x_{1}}\right)_{x_{1}=0}=\theta \\
& \left(\frac{d y_{2}}{d x_{2}}\right)_{x_{2}=0}=-\theta .
\end{aligned}
$$

From Fig. 1, one knows

$$
\begin{aligned}
& U_{1}(0, t)=-X, \\
& U_{2}(0, t)=-Y .
\end{aligned}
$$

$\operatorname{Sin} \theta \cong \theta$ when $\theta<<1$. From Fig. 1 , one obtains 


$$
\begin{aligned}
& y_{1}(0, t)=Y+\theta L, \\
& y_{2}(0, t)=Y-\theta L .
\end{aligned}
$$

From wave equation, one knows

$$
\frac{\partial^{2} U_{1}}{\partial x_{1}^{2}}-\frac{1}{C^{2}} \frac{\partial^{2} U_{1}}{\partial t^{2}}=0,
$$

where

\section{$C=\sqrt{\frac{E}{\rho}}, E$ :Young's modulus, $\rho$ :density.}

Similarly, according to wave equation, one obtains

$$
\frac{\partial^{2} U_{2}}{\partial x_{2}^{2}}-\frac{1}{C^{2}} \frac{\partial^{2} U_{2}}{\partial t^{2}}=0
$$

From the definition of strain, one knows that the horizontal and vertical rod is respectively

$$
\begin{aligned}
& \sigma_{1}=E \frac{\partial U_{1}}{\partial x_{1}}, \\
& \sigma_{2}=E \frac{\partial U_{2}}{\partial x_{2}} .
\end{aligned}
$$

The following three symbols are defined

$\phi_{I}\left(t+\frac{x_{1}}{C}\right):$ the incoming incident longitudinal displacement field,

$\phi_{R}\left(t-\frac{x_{1}}{C}\right):$ the reflected longitudinal wave in the horizontal rod,

$\phi_{T}\left(t-\frac{x_{2}}{C}\right):$ the longitudinal displacement field generated in the vertical rod.

From the displacement compatibility, one knows

$$
\begin{aligned}
& U_{1}\left(x_{1}, t\right)=\phi_{1}\left(t+\frac{x_{1}}{C}\right)+\phi_{R}\left(t-\frac{x_{1}}{C}\right), \\
& U_{2}\left(x_{2}, t\right)=\phi_{T}\left(t-\frac{x_{2}}{C}\right) .
\end{aligned}
$$

Now consider the relationship of welded joints. Setting $x_{1}=0$ into Eq.(13a) and using Eq. (7) one can get

$$
\phi_{I}(0, t)+\phi_{R}(0, t)=-X
$$

Putting $x_{2}=0$ into Eq. (13b) and using Eq. (8), one knows

$$
\phi_{T}(0, t)=-Y
$$

On calculating the axial stresses from Eq. (12a), (12b), (13a) and (13b) and multiplying by the area $4 L^{2}$ to obtain the axial forces $T_{1}$ and $T_{2}$, one finds the equations

$$
\begin{aligned}
& \phi_{I}^{\prime}(0, t)-\phi_{R}^{\prime}(0, t)=\frac{T_{1}}{4 \rho C L^{2}}, \\
& \phi_{T}^{\prime}(0, t)=-\frac{T_{2}}{4 \rho C L^{2}},
\end{aligned}
$$

where $T_{1}$ and $T_{2}$ are the axial forces in horizontal and vertical rod, respectively. Taking the equilibrium of force and moment in the Fig. 1, one gets

$$
\begin{aligned}
& T_{1}+Q_{2}=-8 \rho L^{3} \ddot{X}, \\
& T_{2}+Q_{1}=-8 \rho \dot{L}^{3} \ddot{Y}, \\
& M_{1}-M_{2}+L\left(Q_{2}-Q_{1}\right)=\frac{16 \rho L^{5} \ddot{\theta}}{3} .
\end{aligned}
$$

The boundary conditions at $x_{2}=0$ for the bending moment $M\left(x_{2}, t\right)$ and shear force $Q\left(x_{2}, t\right)$ in the vertical rod are respectively

$$
M(0, t)=M_{2}, Q(0, t)=Q_{2} .
$$

From Fig. 1 and the definition of material strength, one knows

$$
\begin{aligned}
& Q=\frac{\partial M}{\partial x_{2}}, \\
& M=E I_{2}\left(\frac{\partial^{2} y_{2}}{\partial x_{2}^{2}}\right), \\
& m \frac{\partial^{2} y_{2}}{\partial t^{2}}=-\frac{\partial Q}{\partial x_{2}},
\end{aligned}
$$

where $m=4 \rho L^{2}$.

From Eqs. (22), (23) and (24) together with Eqs. (3) and (4), one obtains the equation for transverse waves

$$
\frac{\partial^{4} y_{2}}{\partial x_{2}^{4}}+\frac{3}{C^{2} L^{2}} \frac{\partial^{2} y_{2}}{\partial t^{2}}=0
$$

Using initial conditions $y_{2}\left(x_{2}, 0\right)=0,\left(\frac{d y_{2}}{d x_{2}}\right)$, and applying the Laplace transform, Eq. (25) becomes

$$
\frac{d^{4} \bar{y}_{2}}{d x_{2}^{4}}+\frac{3 p^{2}}{C^{2} L^{2}} \bar{y}_{2}=0 .
$$

Solving Eq. (26) yields

$$
\begin{aligned}
\dot{y}_{2} & =A(p) \exp \left[-(1+i)\left(\frac{a p}{C L}\right)^{1 / 2} x_{2}\right] \\
& +B(p) \exp \left[-(1-i)\left(\frac{a p}{C L}\right)^{1 / 2} x_{2}\right] \\
& +C(p) \exp \left[(1+i)\left(\frac{a p}{C L}\right)^{1 / 2} x_{2}\right] \\
& +D(p) \exp \left[(1-i)\left(\frac{a p}{C L}\right)^{1 / 2} x_{2}\right],
\end{aligned}
$$


where

$$
\alpha=\frac{\sqrt{3}}{2} \cong 0.866 \text {. }
$$

For bounded values of $\tilde{y}_{2}\left(x_{2}, p\right)$, one would have $C(p)=D(p)=0$. Differentiating Eq. (27) twice with respective to $x_{2}$ and substituting into Eq. (23) and putting $x_{2}=0$ yields

$$
\left(\frac{8 E L^{4}}{3}\right)\left(\frac{\alpha p}{C L}\right) i(A-B)=\bar{M}_{2} \text {. }
$$

Differentiating Eq. (27) triple with respective to $x_{2}$ and substituting into Eq. (22) and putting $x_{2}=0$ yields

$$
2\left(\frac{\alpha p}{C L}\right)^{3 / 2}[(1-i) A+(1+i) B]=\frac{3 \bar{Q}_{2}}{4 E L^{4}} .
$$

Let $x_{2}=0$, then Eq. (27) becomes

$$
\bar{y}_{2}(0, p)=A+B .
$$

Differentiating Eq. (27) with respect to $x_{2}$ and then setting $x_{2}=0$, one obtains

$$
\left(\frac{d \dot{y}_{2}}{d x_{2}}\right)_{x_{2}=0}=-\left(\frac{\alpha p}{C L}\right)^{1 / 2}[A+B+i(A-B)] .
$$

Solving Eqs. (29) and (30) for getting A and B and then substituting them into Eqs. (31) and (32), one obtains

$$
\begin{aligned}
& \tilde{y}(0, p)=\frac{3}{8 E L^{4}}\left[\left(\frac{C L}{\alpha p}\right) \bar{M}_{2}+\left(\frac{C L}{\alpha p}\right)^{3 / 2} \bar{Q}_{2}\right], \\
& \left(\frac{d \bar{y}_{2}}{d x_{2}}\right)=-\left(\frac{3}{8 E L^{4}}\right)\left[\left(\frac{C L}{\alpha p}\right) \bar{Q}_{2}+2\left(\frac{C L}{\alpha p}\right)^{1 / 2} \bar{M}_{2}\right] .
\end{aligned}
$$

Taking the Laplace transform with respect to Eq. (10) and comparing with Eq. (33), one gets

$$
\frac{3}{8 E L^{4}}\left[\left(\frac{C L}{\alpha p}\right)^{3 / 2} \bar{Q}_{2}+\left(\frac{C L}{\alpha p}\right) \bar{M}_{2}\right]=\bar{X}-L \bar{\theta} .
$$

Using the Laplace transform with respect to Eq. (6) and comparing with Eq. (34), one gets

$$
\frac{3}{8 E L^{4}}\left[\left(\frac{C L}{\alpha p}\right) \bar{Q}_{2}+2\left(\frac{C L}{\alpha p}\right)^{1 / 2} \bar{M}_{2}\right]=\bar{\theta} .
$$

Similarly, comparing Eq. (33) with Eq. (9), one obtains

$$
\frac{3}{8 E L^{4}}\left[\left(\frac{C L}{\alpha p}\right)^{3 / 2} \bar{Q}_{1}+\left(\frac{C L}{\alpha p}\right) \bar{M}_{1}\right]=\bar{Y}+L \bar{\theta} .
$$
obtains

Similarly, comparing Eq. (34) with Eq. (5), one

$$
\frac{3}{8 E L^{4}}\left[\left(\frac{C L}{\alpha p}\right) \bar{Q}_{1}+2\left(\frac{C L}{\alpha p}\right)^{1 / 2} \bar{M}_{1}\right]=-\bar{\theta} .
$$

Applying the Laplace transform with respect to Eq. (14) to Eq. (20), one gets

$$
\begin{aligned}
& \bar{\phi}_{I}+\bar{\phi}_{R}=-\bar{X}, \\
& \bar{\phi}_{T}=-\bar{Y}, \\
& \bar{\phi}_{I}-\bar{\phi}_{R}=\frac{\bar{T}_{1}}{4 \rho C p L^{2}}, \\
& \bar{\phi}_{T}=-\frac{\bar{T}_{2}}{4 \rho C p L^{2}}, \\
& \bar{T}_{1}+\bar{Q}_{2}=-8 \rho L^{3} p^{2} \bar{X}, \\
& \bar{T}_{2}+\bar{Q}_{1}=-8 \rho L^{3} p^{2} \bar{Y}, \\
& \bar{M}_{1}-\bar{M}_{2}+L\left(\bar{Q}_{2}-\bar{Q}_{1}\right)=\frac{16 \rho L^{5} p^{2} \bar{\theta}}{3} .
\end{aligned}
$$

The incident wave $\bar{\phi}_{1}$ is presumed known. Thus from Eqs. (35) (45), the values of $\bar{M}_{1}, \bar{M}_{2}, \bar{Q}_{1}, \bar{Q}_{2}, \bar{T}_{1}$, $\bar{T}_{1}, \bar{T}_{2}, \bar{\phi}_{R}, \bar{\phi}_{T}, \bar{X}, \bar{Y}$ and $\bar{\theta}$ can be determined. Solving the simultaneous equations mentioned above, one gets

$$
\bar{\phi}_{T}=-\bar{G}(p) p \bar{\phi}_{I},
$$

where

$$
\begin{gathered}
G(p)=\frac{4 \alpha \xi(1+2 \xi)^{2} / 3}{p\left(1+\frac{4 \alpha \xi}{3}+\frac{2 \xi^{2}}{\alpha}\right)\left[\left(1+\frac{4 \alpha \xi}{3}+\frac{2 \xi^{2}}{\alpha}\right)\left(1+\frac{2 \xi^{3}}{\alpha^{2}}\right)+(1+2 \xi)^{2}\right]}, \\
\quad \xi=\left(\frac{\alpha p L}{C}\right)^{1 / 2} .
\end{gathered}
$$

For convenience, the original positive $x_{1}$ direction is reversed. Thus, Eq. (46) becomes

$$
\bar{\phi}_{T}=\bar{G}(p) p \bar{\phi}_{I} .
$$
yields

Applying the convolution integral to Eq. (49)

$$
\phi_{T}=\int_{0}^{t} G\left(t-t^{\prime}\right) \frac{d \phi_{I}\left(t^{\prime}\right)}{d t^{\prime}},
$$

where

$$
G(t) \equiv L^{-1}[G(p)] .
$$

Obviously $G(\mathrm{t})$ is the response for an input step function of unit amplitude for which $d \phi_{I} / \phi_{t}$ is the Dirac delta function; that is

$$
\frac{d \phi_{I}}{d t} \equiv \delta(t) .
$$


On defining a parameter

$$
\tau=\frac{\alpha L}{C}
$$

it is easily proved that $G(t)$ can be denoted in the form

$$
G(t)=X\left(\frac{t}{\tau}\right)
$$

where

$$
X\left(\frac{t}{\tau}\right)=X(x)
$$

Using the Iaplace transform on Eq. (55) gives

$$
\begin{aligned}
\bar{X}(s) & =\int_{0}^{\infty} X(x) e^{-s x} d x \\
& =\frac{4 \alpha\left(1+2 s^{1 / 2}\right)^{2} / 3}{s^{1 / 2}\left(1+\frac{4 \alpha s^{1 / 2}}{3}+\frac{2 s}{\alpha}\right)\left[\left(1+\frac{4 \alpha s^{1 / 2}}{3}+\frac{2 s}{\alpha}\right)\left(1+\frac{2 s^{3 / 2}}{\alpha^{2}}\right)+(1+2 s)^{2}\right]}, \\
& =s^{1 / 2} \bar{Q}\left(s^{1 / 2}\right) .
\end{aligned}
$$

Applying the inverse Laplace transform to Eq. (56) gives

$$
X(x)=\frac{1}{(\pi x)^{1 / 2}} \int_{0}^{\infty} e^{-\frac{u^{2}}{4 x}} Q(u) d u .
$$

Substituting $\alpha=0.866$ into the above equation, one obtains

$$
\begin{aligned}
Q(s) & =\frac{0.0002 s^{4}-3.07934 s^{3}+0.00016 s-1.15462}{\left(6.1589 s^{5}+3.0793 s^{4}+2.6668 s^{3}+6.3094 s^{2}+5.1547 s+2\right)} \\
& +\frac{-0.00007 s+1.15466}{\left(2.3094 s^{2}+1.1547 s+1\right)} .
\end{aligned}
$$

The inverse Laplace transform of Eq. (58) leads

$$
Q(u)=L^{-1}[\bar{Q}(s)]
$$

From Abramowitz and Stegun [8], one gets

$$
\int_{0}^{\infty} e^{-\left(a t^{2}+2 b t+c\right)} d t=\frac{1}{2} \sqrt{\frac{\pi}{a}} e^{\frac{b^{2}-a c}{a}} \operatorname{erfc} \frac{b}{\sqrt{a}},
$$

where

$\operatorname{erfc}(x) \equiv 2 \pi^{-1 / 2} \int_{x}^{\infty} e^{-t^{2}} d t, \operatorname{erf}(x) \equiv 2 \pi^{-1 / 2} \int_{0}^{x} e^{-t^{2}} d t$,

and $w(x+y i)=w(z)$ is the regular function of $z$,

$$
w(z) \equiv e^{-z^{2}}[1-e r f(-i z)] .
$$

Thus, Eq. (56) can be written as

$$
X(x)=0.0423816 e^{0.5840 x}(1-\operatorname{erf}(0.764225 \sqrt{x}))
$$

$$
\begin{aligned}
& +(-0.000015+0.4107 i) w(-0.6087 \sqrt{x}+0.25 \sqrt{x} i) \\
& +(-0.000015-0.4107 i) w(0.6087 \sqrt{x}+0.25 \sqrt{x} i) \\
& +(0.0503946-0.3073 i) w(-0.450343 \sqrt{x}+0.408636 \sqrt{x} i) \\
& +(0.0503946+0.3073 i) w(0.450343 \sqrt{x}+0.408636 \sqrt{x} i) \\
& +(-0.071556+0.039018 i) w(0.925546 \sqrt{x}-0.540764 \sqrt{x} i) \\
& +(-0.071556+0.039018 i) w(-0.925546 \sqrt{x}-0.540764 \sqrt{x} i)
\end{aligned}
$$
tains

After simplifying the above equation, one ob-

$$
\begin{aligned}
X(x) & =0.0423816 e^{0.5840 x}(1-\operatorname{erf}(0.764225 \sqrt{x})) \\
& +\operatorname{Re}[(-0.0003-0.8214 i) w(0.6087 \sqrt{x}+0.25 \sqrt{x i})] \\
& +\operatorname{Re}[(0.10079+0.6146 i) w(0.450343 \sqrt{x}+0.408636 \sqrt{x} i)] \\
& +\operatorname{Re}[(0.143112+0.078036 i) w(0.925546 \sqrt{x} \\
& +0.540764 \sqrt{x} i)]-e^{-0.642 x}[(0.286224 \cos (1.001004 x) \\
& +0.156072 \sin (1.001004 t)]
\end{aligned}
$$

Calculating the $X(x)$ by substituting $x$ values and using the appropriate Table in Abramowitz and Stegun [8] yields Table 1 . When $x>100$, the $x$ values are not influenced by the $X(x)$. Thus

$$
X(x) \cong 0.3098 x^{-1 / 2} \quad \text { when } x>100 .
$$

From Table 1, Fig. 3 can be plotted. For an input unit step function, the response $\phi_{T}$ is directly obtained by $X$. It is worth to point out that the shape of $X$ is independent of the cross-section geometry. However, the time scale $\tau$ depends on $L^{1 / 2}$; for the experiment $L=1.27 \mathrm{~cm}$ and $\tau=2.2 \mu \mathrm{s}$ in [5]. The whole width of the profile of Fig. 3 represent $0.22 \mathrm{~ms}$. Thus Fig. 4 in [5] can be given the values of $\phi$ versus time scale. Fig. 4 in present study obviously make up a deficiency in [5]. Finally substituting Eq. (57) into Eq. (50), one gets

$$
\phi_{T}=\int_{0}^{t} x\left[\left(t-t^{\prime}\right) / \tau\right] \frac{d \phi_{I}\left(t^{\prime}\right)}{d t^{\prime}} d t^{\prime}
$$

From Achenbach [9], one knows

$$
\int_{a}^{b} h(x) \delta^{(n)}\left(x-x^{\prime}\right) d x^{\prime}=\left\{\begin{array}{l}
h^{n}(x), x \in(a, b), \\
0, x \notin(a, b)
\end{array}\right.
$$


Table 1. Values of $X(x)$ corresponding to $x$

\begin{tabular}{cccccc}
\hline$x$ & $\operatorname{erf}(0.7642 \sqrt{x} i)$ & $w(0.6087 \sqrt{x}+0.25 \sqrt{x} i)$ & $w(0.4503 \sqrt{x}+0.4086 \sqrt{x} i)$ & $w(0.9256 \sqrt{x}+0.5408 \sqrt{x} i)$ & $X(x)$ \\
\hline 0 & 0 & 1.0 & 1.0 & 1.0 & 0.00003 \\
0.5 & 0.555256 & $0.7130+0.3239 \mathrm{i}$ & $0.6895+0.2112 \mathrm{i}$ & $0.5151+0.3233 \mathrm{i}$ & 0.033524 \\
1 & 0.720187 & $0.5846+0.3734 \mathrm{i}$ & $0.5843+0.2391 \mathrm{i}$ & $0.3764+0.3179 \mathrm{i}$ & 0.106381 \\
1.5 & 0.814377 & $0.4956+0.3860 \mathrm{i}$ & $0.5166+0.2479 \mathrm{i}$ & $0.3005+0.2994 \mathrm{i}$ & 0.181298 \\
2.0 & 0.873599 & $0.4339+0.3870 \mathrm{i}$ & $0.4666+0.2498 \mathrm{i}$ & $0.2519+0.2785 \mathrm{i}$ & 0.235782 \\
2.5 & 0.912531 & $0.3795+0.3805 \mathrm{i}$ & $0.4277+0.2485 \mathrm{i}$ & $0.2185+0.2596 \mathrm{i}$ & 0.235782 \\
3.0 & 0.938766 & $0.3390+0.3721 \mathrm{i}$ & $0.3959+0.2446 \mathrm{i}$ & $0.1941+0.2435 \mathrm{i}$ & 0.263223 \\
3.5 & 0.956813 & $0.3061+0.3619 \mathrm{i}$ & $0.3698+0.2405 \mathrm{i}$ & $0.1624+0.2855 \mathrm{i}$ & 0.267081 \\
4.0 & 0.969345 & $0.2791+0.3512 \mathrm{i}$ & $0.3479+0.2361 \mathrm{i}$ & $0.1610+0.2173 \mathrm{i}$ & 0.229698 \\
4.5 & 0.978121 & $0.2564+0.3409 \mathrm{i}$ & $0.3286+0.2312 \mathrm{i}$ & $0.1492+0.2066 \mathrm{i}$ & 0.205822 \\
5.0 & 0.984335 & $0.2369+0.3304 \mathrm{i}$ & $0.3122+0.2267 \mathrm{i}$ & $0.1396+0.1971 \mathrm{i}$ & 0.184437 \\
5.5 & 0.988744 & $0.2206+0.3203 \mathrm{i}$ & $0.2976+0.2219 \mathrm{i}$ & $0.1314+0.1892 \mathrm{i}$ & 0.168304 \\
6.0 & 0.99188 & $0.2062+0.3113 \mathrm{i}$ & $0.3034+0.2075 \mathrm{i}$ & $0.1241+0.1816 \mathrm{i}$ & 0.165898 \\
8.0 & 0.997764 & $0.1651+0.2782 \mathrm{i}$ & $0.2449+0.2013 \mathrm{i}$ & $0.1043+0.1587 \mathrm{i}$ & 0.141122 \\
10.0 & 0.999369 & $0.1423+0.2540 \mathrm{i}$ & $0.2172+0.1872 \mathrm{i}$ & $0.0914+0.1426 \mathrm{i}$ & 0.118574 \\
20.0 & 1 & $0.087+0.1812 \mathrm{i}$ & $0.1486+0.1435 \mathrm{i}$ & $0.0623+0.1014 \mathrm{i}$ & 0.076574 \\
30.0 & 1 & $0.0673+0.1481 \mathrm{i}$ & $0.1192+0.1201 \mathrm{i}$ & $0.0499+0.0829 \mathrm{i}$ & 0.060528 \\
40.0 & 1 & $0.0567+0.1279 \mathrm{i}$ & $0.1023+0.1053 \mathrm{i}$ & $0.0429+0.0723 \mathrm{i}$ & 0.05117 \\
50.0 & 1 & $0.0512+0.1142 \mathrm{i}$ & $0.0908+0.0948 \mathrm{i}$ & $0.0382+0.0642 \mathrm{i}$ & 0.045147 \\
60.0 & 1 & $0.0452+0.1041 \mathrm{i}$ & $0.0825+0.0869 \mathrm{i}$ & $0.0348+0.0642 \mathrm{i}$ & 0.045147 \\
70.0 & 1 & $0.0415+0.0963 \mathrm{i}$ & $0.0761+0.0807 \mathrm{i}$ & $0.0321+0.0543 \mathrm{i}$ & 0.037528 \\
80.0 & 1 & $0.0386+0.0919 \mathrm{i}$ & $0.0714+0.0756 \mathrm{i}$ & $0.0308+0.0508 \mathrm{i}$ & 0.0349463 \\
90.0 & 1 & $0.0363+0.0848 \mathrm{i}$ & $0.0669+0.0715 \mathrm{i}$ & $0.0283+0.0479 \mathrm{i}$ & 0.0327647 \\
100.0 & 1 & $0.0342+0.0804 \mathrm{i}$ & $0.0633+0.0679 \mathrm{i}$ & $0.0268+0.0454 \mathrm{i}$ & 0.03098 \\
\hline & & & & & 0.04
\end{tabular}

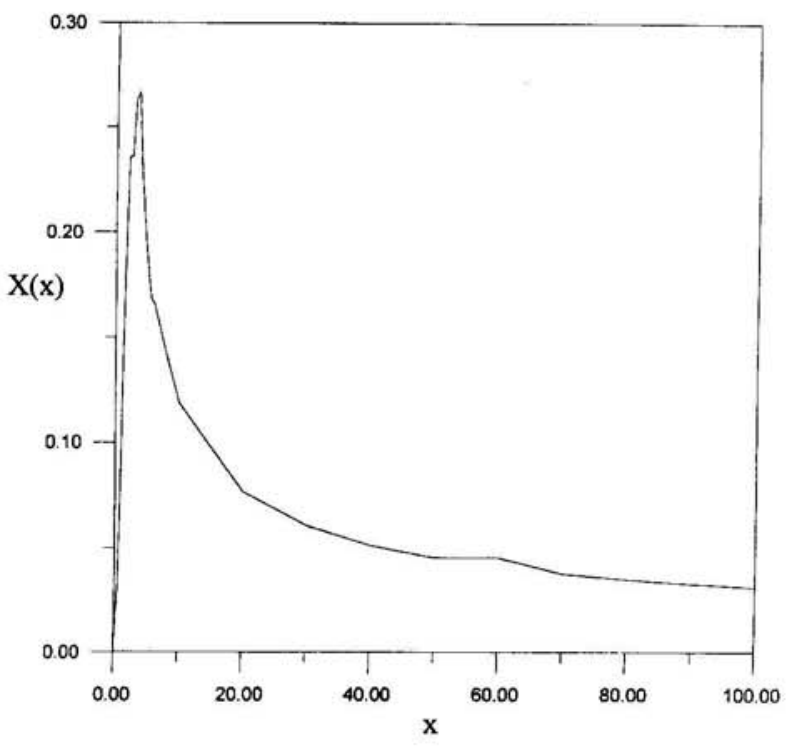

Fig. 3. Values of $\mathrm{X}(\mathrm{x})$ corresponding to $\mathrm{x}$.

Thus, Eq. (50) can be simplified as

$$
\begin{aligned}
\phi_{T} & =X(t), \\
& =0.0423816 e^{0.5840 t}(1-\operatorname{erf}(0.764225 \sqrt{t})) \\
& +\operatorname{Re}[(-0.00003-0.8214 i) w)(0.6087 \sqrt{t}
\end{aligned}
$$

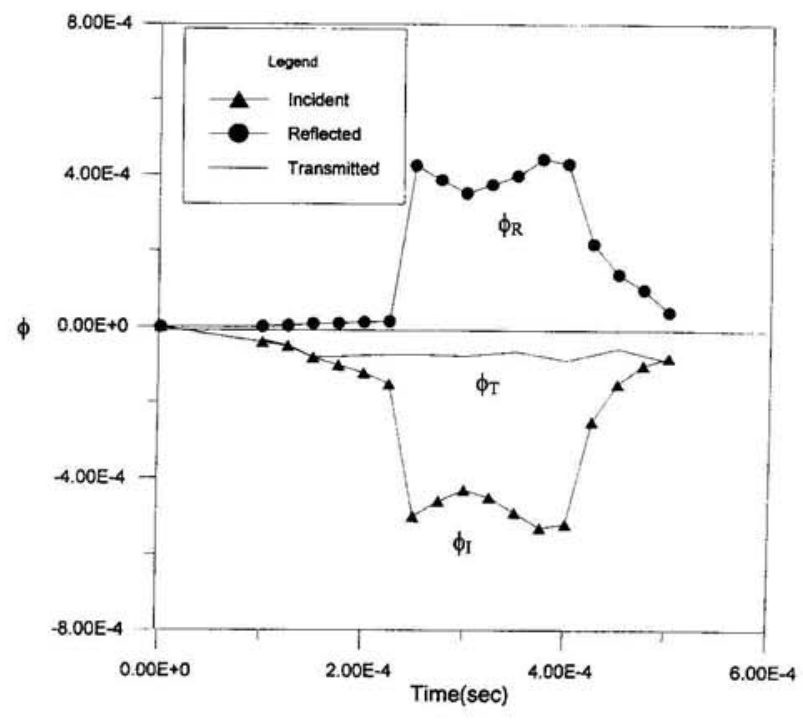

Fig. 4. Values of $\phi$ versus time.

$+0.25 \sqrt{t} i)]+\operatorname{Re}[(0.10079+0.6146 i) w(0.450343 \sqrt{ } t$

$+0.408636 \sqrt{t} i)]+\operatorname{Re}[0.143112$

$+0.078036 i) w(0.925546 \sqrt{t}+0.540764 \sqrt{t} i)]$

$-e^{-0.5642 t}[0.286224 \cos (1.001004 t)$

$+0.156072 \sin (1.001004 t)]$. 
Table 2. The time interval needed action and the obtained values of transmitted longitudinal waves for three different sizes of steel rod. The dimensions of $\mathrm{sr}-1, \mathrm{sr}-2$ and $\mathrm{sr}-3$ are $\mathrm{a}=1.219 \mathrm{~m}, 1.5 \mathrm{~m}, 1.0 \mathrm{~m}, \mathrm{~b}=0.025 \mathrm{~m}, 0.03 \mathrm{~m}, 0.02 \mathrm{~m}, \mathrm{c}=0.025 \mathrm{~m}$, $0.03 \mathrm{~m}, 0.02 \mathrm{~m}$ and $\mathrm{d}=1.219 \mathrm{~m}, 1.5 \mathrm{~m}, 1.0 \mathrm{~m}$, respectively

\begin{tabular}{|c|c|c|c|c|c|c|c|c|}
\hline $\mathrm{t}(\mathrm{sec})$ & $\begin{array}{l}\mathrm{sr}-1 \\
(\mathrm{t} / \tau)\end{array}$ & $\phi_{T}$ & $\mathrm{t}(\mathrm{sec})$ & $\begin{array}{l}\mathrm{sr}-2 \\
(\mathrm{t} / \tau)\end{array}$ & $\phi_{T}$ & $\mathrm{t}(\mathrm{sec})$ & $\begin{array}{l}\mathrm{sr}-3 \\
(\mathrm{t} / \tau)\end{array}$ & $\phi_{T}$ \\
\hline 0.00024 & 112.15 & 0.0293 & 0.00030 & 116.73 & 0.0291 & 0.00020 & 116.55 & 0.0291 \\
\hline 0.00026 & 121.50 & 0.0280 & 0.00034 & 132.31 & 0.0269 & 0.00024 & 139.86 & 0.0262 \\
\hline 0.00028 & 130.84 & 0.0273 & 0.00038 & 147.86 & 0.0255 & 0.00028 & 163.17 & 0.0242 \\
\hline 0.00030 & 140.19 & 0.0260 & 0.00042 & 163.42 & 0.0242 & 0.00032 & 186.48 & 0.0227 \\
\hline 0.00032 & 149.53 & 0.0253 & 0.00046 & 178.99 & 0.0232 & 0.00036 & 209.79 & 0.0214 \\
\hline 0.00034 & 158.88 & 0.0246 & 0.00050 & 194.55 & 0.0222 & 0.00040 & 233.10 & 0.0203 \\
\hline 0.00036 & 168.22 & 0.0239 & 0.00054 & 210.17 & 0.0212 & 0.00044 & 256.41 & 0.0193 \\
\hline 0.00038 & 177.57 & 0.0233 & 0.00058 & 225.68 & 0.0206 & 0.00048 & 279.72 & 0.0185 \\
\hline 0.00040 & 186.92 & 0.0227 & 0.00062 & 241.25 & 0.0199 & 0.00052 & 303.03 & 0.0178 \\
\hline 0.00042 & 196.26 & 0.0221 & 0.00066 & 256.81 & 0.0193 & 0.00056 & 326.34 & 0.0171 \\
\hline 0.00044 & 205.61 & 0.0216 & 0.00070 & 272.37 & 0.0188 & 0.00060 & 349.65 & 0.0166 \\
\hline 0.00046 & 214.95 & 0.0211 & 0.00074 & 287.94 & 0.0183 & & & \\
\hline 0.00048 & 224.31 & 0.0207 & 0.00078 & 303.50 & 0.0178 & & & \\
\hline 0.00050 & 233.65 & 0.0202 & 0.00082 & 319.07 & 0.0173 & & & \\
\hline 0.00052 & 242.99 & 0.0199 & 0.00086 & 334.67 & 0.0169 & & & \\
\hline 0.00054 & 252.34 & 0.0195 & 0.00090 & 350.20 & 0.0165 & & & \\
\hline 0.00056 & 261.68 & 0.0192 & & & & & & \\
\hline 0.00058 & 271.03 & 0.0188 & & & & & & \\
\hline 0.00060 & 280.37 & 0.0185 & & & & & & \\
\hline 0.00062 & 289.72 & 0.0182 & & & & & & \\
\hline 0.00064 & 299.07 & 0.0179 & & & & & & \\
\hline 0.00066 & 308.41 & 0.0176 & & & & & & \\
\hline 0.00068 & 317.76 & 0.0174 & & & & & & \\
\hline 0.00070 & 327.10 & 0.0171 & & & & & & \\
\hline 0.00072 & 336.45 & 0.0169 & & & & & & \\
\hline
\end{tabular}

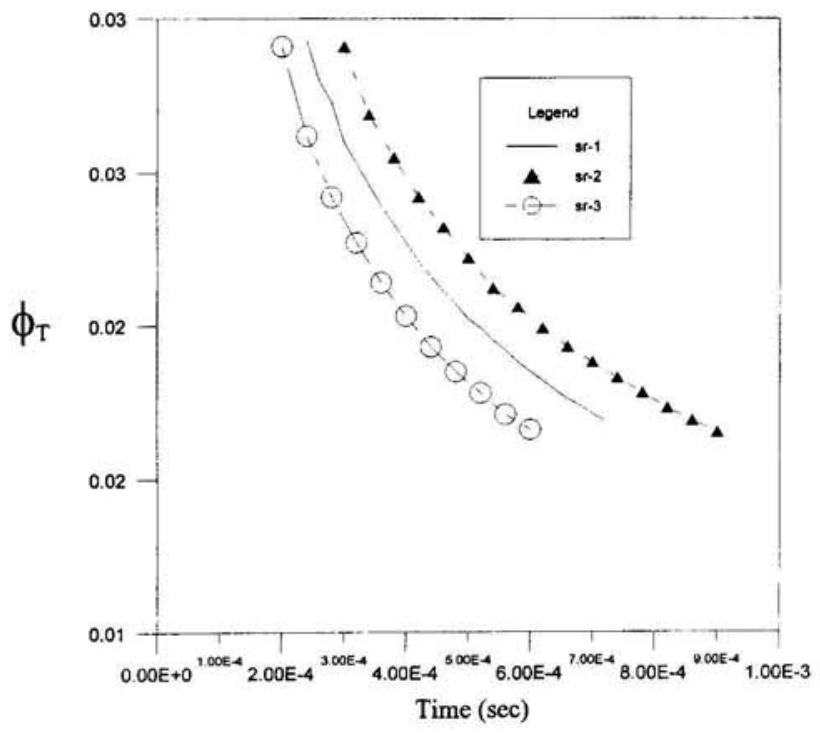

Fig. 5. Values of $\phi_{T}$ versus time.

Using the incident wave in Eq. (66) as the input function in the integral, the theoretical values of $\phi_{T}$ can be computed numerically.

\section{ILLUSTRATIVE EXAMPLE}

Assume that the physical properties of welded joint are the same as the steel rod. Fig. 1 indicates the physical characteristics of the steel rods. For the calculating convenience, one assumes that the welded joint has the equal size, i.e. length, width and thickness are equal each other. The thickness of welded joint is the same as that of rod. The three different size of steel rod are adopted and listed in Table 2. Because the adopted steel rod is of different size, the time of action is also not the same. Using Eq. (68), the time interval needed action and the obtained values of transmitted longitudinal elastic waves for three different size of steel rod is denoted in Table 2. From Table 2, Fig. 5 can be plotted.

\section{DISCUSSIONS}

Atkins and Hunter[5] used Eq. (66) as the input 
function in the integral, the theoretical $\phi_{T}$ is computed numerically and compared with the experimental profile in Fig. 9 in [5]. They pointed out that the agreement is good except perhaps at the peak amplitude, where the theoretical value exceeds the experiment one by about $25 \%$. Eq. (66) was utilized by Simha and Fourney[6] for the theoretical determination of the transmitted longitudinal elastic wave. They pointed out again that the transmitted longitudinal elastic wave amplitude is as most as 25 percent of the incident elastic wave amplitude. In this paper, one knows from Table 2 or Fig. 5 that the transmitted longitudinal elastic waves are almost not existed; that is, the maximum values of the transmitted wave is the values of $3 \%$ of the incident longitudinal waves. This is occurred that boundary conditions are satisfied the condition of compatibility while vertical rod is asymmetry. Thus, the coupling action is happen and the infinitesimal values of transmitted longitudinal elastic wave in vertical rod is existed. The numerical results in this paper is very agreed the results obtained by Lee and Kolsky [2].

\section{CONCLUSIONS}

The problem of elastic longitudinal wave propagated in the $L$-type welded rod has been described. In the process of theoretical derivation, one knows that the values of infinitesimal deformation of the transmitted longitudinal elastic waves are of obvious relationship with the size of welded joint of the steel rod. The different size of welded joint will be accompanied with the different values of transmitted longitudinal elastic waves. The present study indicates that when the horizontal rod of $L$-type welded steel rod was applied a force, the longitudinal elastic wave through the welded joint nearly can not transmit into the vertical rod. In this paper, the value of $\phi_{T}$ is only considered. Basically, the other unknown values such as $\phi_{R}, X, Y$, etc. can adopt the same method to calculate them.

\section{NOMENCLATURE}

$\begin{array}{ll}A & \text { cross-sectional area } \\ C & \text { wave velocity } \\ E & \text { Young's modulus } \\ G & \text { shear modulus } \\ G(t), G(p) & \text { function }\end{array}$

moment of inertia for mass the second moment of inertia moment axial force shear force displacement unit weight Poisson's ratio density incident longitudinal elastic wave reflected longitudinal elastic wave transmitted longitudinal elastic wave

\section{REFERENCES}

1. Mandel, J.A., Mathur, R.K., and Chang, Y.C., "Stress Wave at Elastic Right Angle Joint," Journal of the Engineering Mechanics Division, ASCE, Vol. 97, No. EM 4, Aug., pp. 1173-1186 (1971).

2. Lee, J.P., and Kolsky, H., "The Generation of Stress Pulses at the Junction of Two Noncollinear Rods," Journal of Applied Mechanics, ASME, Vol. 39, pp. 809-813 (1972).

3. Timoshenko, S.P., "On the Correction for Shear of the Differential Equations for Transverse Vibrations of Prismatic Bars," Philosophical Magazine, Vol. 41, Series 6 (1921).

4. Timoshenko, S.P., "On the Transverse Vibrations of Bars of Uniform Cross-section," Philosophical Magazine, Vol. 43, Series 6 (1922).

5. Atkins, K.J., and Hunter, S.C., "The Propagation of Longitudinal Elastic Waves Around Right-Angled Corners in Rods of Square Cross-section," Quarterly Journal of Mechanics and Applied Mathematics, Vol. 28, May, pp. 245-260 (1975).

6. Simha, K.R.Y. and Fourney, W.L., "Investigation of Stress Wave Propagation Through Intersecting Bars," Journal of Applied Mechanics, ASME, Vol. 51, pp. 345-353 (1984).

7. Wu, C. M. and Lundberg, B., "Reflection and Transmission of the Energy of Harmonic Elastic Waves in A Bent Bar," Journal of Sound and Vibration, Vol. 190, No. 4, pp. 645-659 (1996).

8. Abramowitz, M. and Stegun, I.A., Handbook of Mathematical Function, Dover Publication, INC. New York, 1046 pp (1954).

9. Achenback, J.D., Wave Propagation in Elastic Solids, Third Edition, North Holland Publishing Company, New York, 425pp (1980). 
縱向彈性波在兩根直角焊接桿件之 研究

梁 明德 陳秋 鎮

國立堂沙海洋大學河海工程研究所

摘 要

在一般的銅骨結構中, 直角焊接是最常見也 是使用頻率最高的焊接样式。本文的主要目的是研 究二根長薄桿將其焊接成 $90^{\circ}$ 的 L型交叉桿件後, 藉 由作用力作用在水平桿件之端點上, 經由縱向彈性 波波傅特性探討當波入射在焊接點上, 隨之所産生 波的反射或透射問題, 利用理論的推導及數值的㖕 算去验證當织向彈性波行經 L 型桿件的焊接點上 時, 研究結果發現縱向彈性波透射值在垂直桿件幾 乎是微量的。 